\title{
Assessment of the health utility of patients with leukemia in China
}

\author{
Xueyun Zeng ${ }^{1 \dagger}$, Mingjie Sui ${ }^{1 \dagger}$, Rui Liu ${ }^{1 \dagger}$, Xinyu Qian ${ }^{2}$, Wenfeng Li ${ }^{3}$, Erwei Zheng ${ }^{4}$, Jinjin Yang ${ }^{1}$, Jinmei Li ${ }^{5}$, \\ Weidong Huang ${ }^{1 *} \mathbb{D}$, Hongbin Yang ${ }^{6 *}$, Hongjuan $\mathrm{Yu}^{3,7^{*}}$ and Nan LuO ${ }^{2}$
}

\begin{abstract}
Objectives: This study aimed to assess the health utility of leukemia patients in China using the EQ-5D-5L, compare it with the population norms, and identify the potential factors associated with health utility.

Methods: A hospital based cross-sectional survey was conducted in three tertiary hospitals from July 2015 to February 2016. A total of 186 patients with leukemia completed the EQ-5D-5L and their health utility scores were calculated using the Chinese value set. EQ-5D-5L utility and dimensions scores of leukemia patients were compared with China's population norms using Kruskal-Wallis test and chi square test. Potential factors associated with health utility were identified using Tobit regression.
\end{abstract}

Results: The mean EQ-5D-5L utility scores of patients with leukemia, grouped by either gender or age, were significantly lower than those of the general population $(p<0.001)$. The same results were found for individual dimensions of EQ-5D-5L, where leukemia patients reported more health problems than the general population $(p<0.001)$. The utility score of leukemia patients was found to be significantly related to medical insurance, religious belief, comorbidities, social support and ECOG performance status.

Conclusion: This study indicated that leukemia patients have worse health status compared to the general population of China and that multiple factors affect the health utility of the patients. The utility scores reported in this study could be useful in future cost-utility analysis.

Keywords: Leukemia, Health utility, EQ-5D-5L, Cancer

\section{Introduction}

Leukemia is a malignant tumor that is common in both children and adults. Leukemia was estimated to be responsible for 309,006 deaths in 2018 and 437,033 new leukemia cases were diagnosed in the same year [1]. China has one of the largest leukemia populations in

\footnotetext{
*Correspondence: weidong218@126.com; Yang21hongbin@163.com; yuhongjuan2008@163.com

${ }^{+}$Xueyun Zeng, Mingjie Sui and Rui Liu contributed equally to this work

1 School of Health Management, Harbin Medical University, Harbin 150086, China

${ }^{3}$ Department of Hematology, The First Affiliated Hospital of Harbin Medical University, Harbin 150001, China

${ }^{6}$ Department of Medical Oncology, Third Affiliated Hospital of Harbin Medical University, Harbin 150081, China

Full list of author information is available at the end of the article
}

the world with 75,300 new cases in 2015 [2]. With novice treatment options available in China, the five-year survival rate of leukemia patients improved from 19.6\% in $2003-2005$ to $25.4 \%$ in $2012-2015$ [3]. While survivability is favorable, surviving patients may, however, be affected by treatment toxicity, increased risk of second malignancy and side effects $[4,5]$. Therefore, Healthrelated quality of life (HRQoL) is an important concern in patients with leukemia [6].

Disease-specific instruments like the European Organization for Research and Treatment of Cancer Quality of Life Core Questionnaire 30 (EORTC QLQ-C30), Medical Research Council/EORTC Quality of Life Questionnaire Leukemia Module (MRC/EORTC QLQ-LEU), Functional Assessment of Cancer Therapy-General original author(s) and the source, provide a link to the Creative Commons licence, and indicate if changes were made. The images or other third party material in this article are included in the article's Creative Commons licence, unless indicated otherwise in a credit line to the material. If material is not included in the article's Creative Commons licence and your intended use is not permitted by statutory regulation or exceeds the permitted use, you will need to obtain permission directly from the copyright holder. To view a copy of this licence, visit http://creativecommons.org/licenses/by/4.0/. The Creative Commons Public Domain Dedication waiver (http://creativeco mmons.org/publicdomain/zero/1.0/) applies to the data made available in this article, unless otherwise stated in a credit line to the data. 
(FACT-G) and the Functional Assessment of Cancer Therapy-Leukemia(FACT-Leu) are commonly used to measure the HRQoL of patients with leukemia [6-10]. While they are valid and reliable, they cannot be used to generate health utility value for leukemia patients because they are not preference-based instruments [11].

Health utility, representing the strength of an individual's preferences for different health states, can be used to summarize HRQoL into a numeric index ranging from 0 to 1 [12]. EQ-5D is currently one of the most widely used standardized multi-attribute utility instruments (MAUIs) [13] for cost-utility analysis (CUA) of healthcare [14]. It is recommended by a number of bodies and guidelines including the National Institute for Health and Care Excellence (NICE) in the UK [15].

Three versions of EQ-5D are available including EQ5D-Y for children, EQ-5D-3L and EQ-5D-5L for adults. EQ-5D-3L has been widely used to measure, compare and value health status across disease areas including leukemia populations [16]. EQ-5D-5L was developed to improve the measurement properties of EQ-5D-3L such as ceiling effect and sensitivity [17]. Ever since, scoring algorithms of EQ-5D-5L based on the general public's health preferences were developed in many countries such as China [18], the UK [19] and Germany [20]. While EQ-5D-5L has been applied to cancer patients [11], It is rarely used to measure health status and health utility of patients with leukemia.

In order to fill these gaps, we therefore assessed the utility scores of leukemia patients using EQ-5D-5L and compared them with the norms for the general adult Chinese population, and identified the potential factors associated with health utility in leukemia.

\section{Methods}

\section{Study design and data collection}

We consecutively recruited patients from three tertiary hospitals in Harbin, Heilongjiang province, northeast China. The hospitals are the centers for leukemia treatment in the region and therefore their leukemia patients are representative. The inclusion criteria of patients were: (1) a diagnosis of leukemia; (2) aged 18 or above; (3) able to understand the questionnaire well. After obtaining informed consent, a face-to-face interview was conducted in a private room by a trained student from Harbin Medical University. The interviews were conducted from July 2015 to February 2016. In order to ease the burdens of respondents and ensure accuracy of information, some clinical information was collected from doctors/nurses (e.g., types of leukemia). Ethical permission (HMUIRB2014012) was granted by the Regional Ethical Committee, Harbin Medical University.
Following suggestions in the literature [5, 7, 21-25], we developed a questionnaire with a three-part structure for information collection: (1) socio-demographic information; (2) clinical information; and (3) health status of patients. Socio-demographic information included gender, age, ethnicity, religious belief, level of education, marital status, medical insurance and annual household income. For assessing religious belief, we set a question 'Do you have any religious belief ? (yes/no). Clinical information included type of leukemia, duration since diagnosis, performance status and comorbidities. The interviewer administered standardized instruments to measure the health status of patients including emotional distress with the Hospital Anxiety and Depression Scale (HADS), perceived social support with the Social Support Self-Rating Scale (SSRS), family function with the APGAR scale, and health utility with EQ-5D-5L.

\section{Measurements}

EQ-5D-5L As a preference-based instrument, EQ5D-5L consists of two parts: the EQ-5D-5L descriptive system and the EQ Visual Analogue Scale (EQ-VAS). With the descriptive system, EQ-5D-5L can define 3,125 $\left(=5^{5}\right)$ health states in the context of five levels (no problems, slight problems, moderate problems, severe problems, and extreme problems) and 5 dimensions (mobility, selfcare, usual activities, pain/discomfort, anxiety/depression). Each heath state can be converted into a utility score using a country-specific value set based on social preferences [26]. In this study, we calculated health utility score of patients with leukemia using the Chinese value set which generates the maximal preference weight of 1 and the minimal preference weight of -0.391 [18].

HADS The Hospital Anxiety and Depression Scale [27] (HADS) is a self-rating scale to assess emotional distress in non-psychiatric patients. HADS measures the anxiety and depression using 14 items including 7 item for anxiety and 7 items for depression. The two subscales have the same score range from 0 to 21 , with the severity of depression or anxiety being categorized as normal (0-7), mild (8-10), moderate (11-14), or severe (15-21) [28]. We used the validated Chinese version of HADS.

SSRS The Social Support Self-Rating Scale (SSRS) developed by Xiao [29] is one of most frequently used instruments for measuring social support in China. SSRS consists of 10 items which form three subscales: subjective support (4 items), objective support ( 3 items), and utilization of social support ( 3 items). The total support score ranges from 12-66; the level of social support can be classified into three categories: low $(\leq 22)$, moderate (23-44), and high (45-66). 
APGAR The family function of patients was measured using the validated family APGAR scale[30]. The APGAR scale consists of five questions measuring five components of family function (adaptation, partnership, growth, affection, and resolve), with three possible answers ("almost never" $=0$, "sometimes" $=1$, "almost always" $=2$ ). The sum of scores range from zero to ten and family function can be classified as either severely dysfunctional (0-3), moderately dysfunctional (4-6), or highly functional $(7-10)$.

ECOG The performance status is an important part of leukemia and was accessed using the Eastern Cooperative Oncology Group (ECOG) scale. Interviewers collected records from doctors who rated the grade of patient with the range from 0 (fully functional and asymptomatic) to 4 (bed ridden) [31].

\section{Statistical analysis}

We described the basic characteristics of the sample using mean and standard deviation (SD) for continuous variables and frequency and percentage for categorical variables. The distribution of the EQ-5D-5L health utility score was skewed, therefore, the Wilcoxon signed-rank test was used to compare the utility score of respondents with the general Chinese population [32]. Since the agegender profiles of the patients and the general population were different, we used the normative data to calculate expected mean utility scores for the patients by adjusting for age and gender [33]. In addition, patients' responses to the five dimensions of EQ-5D-5L were compared to the general population norms and the significance of the difference was determined using the Chi-square test.

To explore the factors associated with utility score, we compared the utility scores of patients with different socio-demographics (gender, age, ethnicity, religious belief, level of education, marital status, medical insurance, annual household income), clinical characteristics (types of leukemia, duration since diagnosis, ECOG score, comorbidities), and psychosocial characteristics (anxiety, depression, social support, family function). The variables that were significantly associated with the health utility score in the Kruskal-Wallis test $(p<0.05)$ will be entered to a Tobit regression model. Despite the reduced ceiling effect of using EQ-5D-5L, 23.5\% of the patients reported full health $(11,111)$. We therefore selected the Tobit regression model to address the distribution of censored data [34].

\section{Results}

\section{Basics of sample}

Of 208 eligible patients with acute myeloid leukemia (AML) and acute lymphoblastic leukemia (ALL), 22 patients refused to complete the survey with the following reasons: 10 patients felt 'uncomfortable', 8 patients 'lacked interest', and 4 patients did not 'understand the informed consent'. In the end, 186 patients with leukemia completed the questionnaires independently.

The mean age of patients was 46 years old and the average duration since diagnosis was 21.7 months. The majority was Han nationality (96.2\%), married (81.2\%), had religious belief (88.2\%) and medical insurance (91.4\%). Most of them had middle or high school qualifications (59.7\%), and reported annual household income ranging from 40,001 to 79,999 Chinese Yuan (approximately 5700 to 11,400 in US Dollar) (48.9\%). The mean score of the patients was 10.9 for anxiety, 7.9 for depression, 37.2 for social support, and 6.9 for family function (Table 2).

\section{Utility scores of leukemia patients versus population norms}

Figure 1 depicts the comparison of utility scores between leukemia patients and population norms for EQ-5D-5L in China. Patients had a significantly lower utility score than the population norms $(0.774$ vs. $0.958, p<0.001)$. The utility score of patients with leukemia grouped by gender and age were also significantly lower than andand gender-specific population norms $(p<0.001)$.

\section{EQ-5D-5L dimensions}

The highest proportion of the 'no problems' response was observed in the 'self-care' dimension (62.9\%), followed by 'usual activities' (62.4\%), 'mobility' (62.4\%), 'pain/discomfort' (47.8\%), and 'anxiety/depression' (39.8\%). A total of 45 patients $(24.2 \%)$ reported no problems in all five dimensions. The proportion of leukemia patients who reported problems in the five dimensions was significantly higher than that of the general population (Table 1).

\section{Univariate analysis of utility score}

The overall EQ-5D-5L utility mean score was 0.774 , while the mean EQ-VAS score was 74.4. The utility scores were higher among those with religious belief $(p=0.036)$, had medical insurance $(p=0.001)$, and did not had comorbidities $(p<0.001)$. In addition, those patients with lower social support $(p<0.001)$, higher family function score $(p<0.001)$, and higher ECOG performance status $(p<0.001)$ had lower utility scores (Table 2$)$.

\section{Factors associated with health utility score}

The results of Tobit regression analysis are displayed in Table 3. Higher utility score was significantly associated with religious belief $(p=0.017)$, medical insurance $(p=0.003)$, absence of comorbidities $(p=0.002)$, higher level of social support $(p=0.007)$, and lower ECOG performance status $(p=0.016)$. 


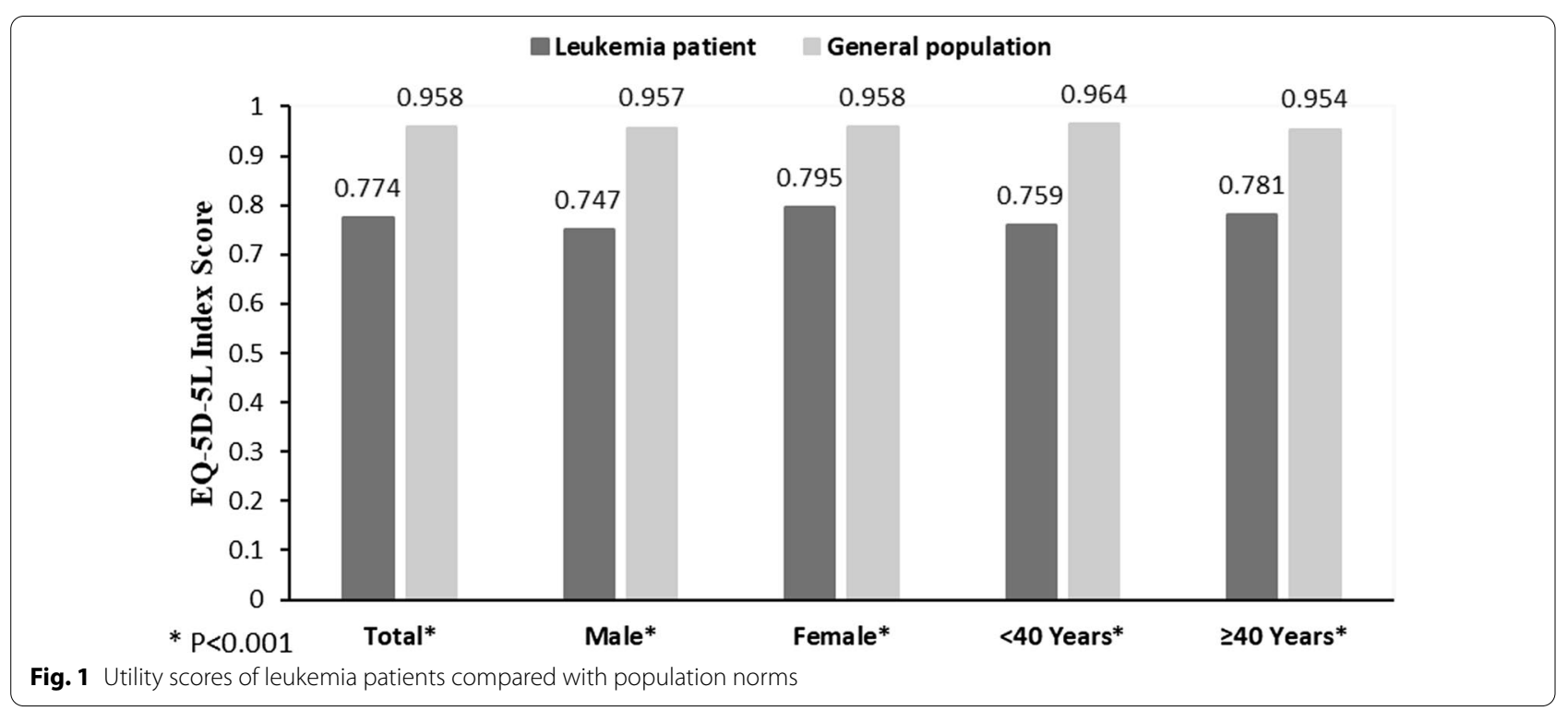

\section{Discussion}

To the best of our knowledge, this study was the first to examine the utility score of patients with leukemia using EQ-5D-5L in China. Being a malignant tumor, leukemia-related policy development is increasingly opting for CUA to assist health resource allocation. We calculated the utility scores of leukemia patients using a representative sample of leukemia with a Chinese value set. Therefore, the baseline utility score could be used for calculating the quality-adjusted life year (QALY) which is a central input in the CUA of health care for leukemia.

The mean utility of patients, even after adjustment of age or gender, was lower than the general Chinese population. This is similar to the finding in a prior study of patients with CLL in Netherlands population [22]. Other studies of leukemia patients using FACT-G [7] and EQ-VAS [35] shown similar trend. The mean utility score $(0.778)$ in this study was a little lower than the mean of utility (0.81) [22] in patients from Netherland. The possible reasons for this difference could be due to cultural, clinical and socioeconomic characteristics of the two samples. Furthermore, utility scores calculated in this study could be more accurate that scores derived from mapping in previous studies [22]. In addition, the patients reported more problems in all five dimensions than general population. The current results together with prior related studies highlighted the negative impact of leukemia on HRQoL of patients.

Religious belief could be an important aspect that help cancer patients find meaning in life [36], get support [37], and provide comfort [38]. A recent meta-analysis found that greater religious belief is associated with better HRQoL in cancer patients including those with leukemia
[39]. This relationship was also confirmed in the current study. These results underscore the importance of patients' religion as part of comprehensive leukemia care. China is a multi-religion country and the number of religious believers is growing exponentially, despite being relatively lower compared to other Asian countries [40]. Given that the finding about the relationship between religion and HRQoL in the leukemia population is limited in China, further empirical research is needed.

The finding that patients not covered by medical insurance reported lower health utility was consistent with previous studies in leukemia [41] and other solid tumors [34]. Although prognosis of leukemia is relatively less detrimental than other forms of cancer, it requires longterm treatment, rehabilitation, and care which could be costly [41, 42]. The protecting effect of medical insurance could be due to the peaceful mind it brings to the patients. Patients with medical insurance might have experienced extra mental stress and fear which negatively affected their HRQoL [43, 44]. Moreover, it is possible that patients with medical insurance received novel treatments that are costly but more effective. Unfortunately, we are not able to test this hypothesis because of unavailability of treatment data. Future studies should further investigate the effect of medical insurance on patients' HRQoL.

In the treatment of leukemia, patients often were accompanied by comorbidities such as infection, bleeding, anemia, and fatigue. These comorbidities could deteriorate the health of patients and their HRQoL. In addition, the results also confirmed that HRQoL worsens with lower ECOG performance status. These findings were in line with prior limited data exist on 


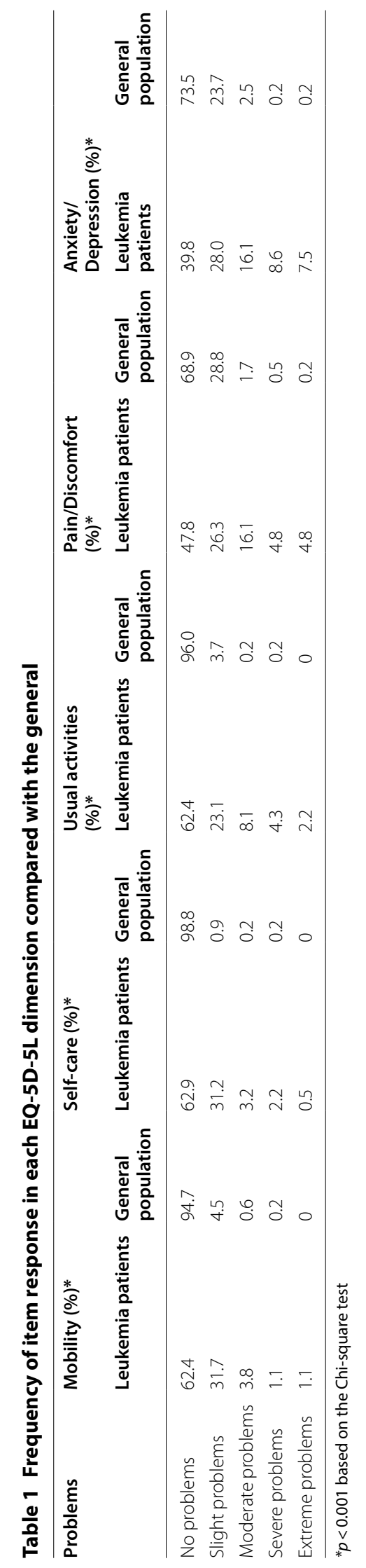


Table 2 Utility scores of EQ-5D-5L of respondents in different characteristics

\begin{tabular}{|c|c|c|c|c|c|}
\hline & $N=186$ & Mean \pm SD & Median(range) & $95 \% \mathrm{Cl}$ & $P$ values \\
\hline Gender & & & & & 0.248 \\
\hline Male & $86(46.2 \%)$ & $0.751 \pm 0.274$ & $0.846(-0.222-1)$ & $0.692-0.809$ & \\
\hline Female & $100(53.8 \%)$ & $0.795 \pm 0.246$ & $0.882(-0.251-1)$ & $0.746-0.844$ & \\
\hline Age (years, mean $\pm S D$ ) & $45.77 \pm 14.30$ & & & & 0.584 \\
\hline$\leq 37$ & $60(32.3 \%)$ & $0.759 \pm 0.289$ & $0.848(-0.251-1)$ & $0.685-0.834$ & \\
\hline$>37$ & $126(67.7 \%)$ & $0.782 \pm 0.245$ & $0.882(-0.222-1)$ & $0.738-0.825$ & \\
\hline Ethnicity & & & & & 0.453 \\
\hline Han & $179(96.2 \%)$ & $0.777 \pm 0.260$ & $0.882(-0.251-1)$ & $0.739-0.815$ & \\
\hline Other & $7(3.8 \%)$ & $0.702 \pm 0.266$ & $0.771(0.329-1)$ & $0.456-0.948$ & \\
\hline Religious belief & & & & & $0.036^{*}$ \\
\hline No & $164(88.2 \%)$ & $0.764 \pm 0.267$ & $0.848(-0.251-1)$ & $0.723-0.805$ & \\
\hline Yes & $22(11.8 \%)$ & $0.849 \pm 0.187$ & $0.893(0.262-1)$ & $0.767-0.932$ & \\
\hline Level of education & & & & & 0.916 \\
\hline No more than primary school & $31(16.7 \%)$ & $0.757 \pm 0.237$ & $0.848(-0.017-1)$ & $0.670-0.843$ & \\
\hline Middle or high school & $111(59.7 \%)$ & $0.779 \pm 0.280$ & $0.893(-0.251-1)$ & $0.726-0.831$ & \\
\hline University & $44(23.7 \%)$ & $0.776 \pm 0.222$ & $0.804(0.083-1)$ & $0.709-0.844$ & \\
\hline Marital status & & & & & 0.731 \\
\hline Married & $151(81.2 \%)$ & $0.778 \pm 0.256$ & $0.882(-0.251-1)$ & $0.736-0.819$ & \\
\hline Other & $35(18.8 \%)$ & $0.761 \pm 0.277$ & $0.848(0.022-1)$ & $0.668-0.856$ & \\
\hline Medical insurance & & & & & $<0.001^{* *}$ \\
\hline No & $16(8.6 \%)$ & $0.400 \pm 0.454$ & $0.345(-0.251-1)$ & $0.158-0.642$ & \\
\hline Yes & $170(91.4 \%)$ & $0.810 \pm 0.202$ & $0.882(-0.164-1)$ & $0.779-0.840$ & \\
\hline Annual household income(CNY¥/USD \$) & & & & & 0.223 \\
\hline$\leq 40,000 / 5700$ & $86(46.2 \%)$ & $0.741 \pm 0.284$ & $0.848(-0.251-1)$ & $0.681-0.802$ & \\
\hline 40,001/5700-79,999/11,400 & $91(48.9 \%)$ & $0.797 \pm 0.242$ & $0.893(-0.222-1)$ & $0.747-0.848$ & \\
\hline$\geq 80,000 / 11,000$ & $9(4.8 \%)$ & $0.857 \pm 0.132$ & $0.894(0.634-1)$ & $0.755-0.959$ & \\
\hline Types of leukemia & & & & & 0.066 \\
\hline ALL & $18(9.7 \%)$ & $0.668 \pm 0.3$ & $0.748(-0.222-1)$ & $0.519-0.817$ & \\
\hline AML & $168(90.3 \%)$ & $0.786 \pm 0.253$ & $0.889(-0.251-1)$ & $0.747-0.824$ & \\
\hline Duration since diagnosis & $21.67 \pm 20.16$ & & & & 0.857 \\
\hline$\leq 12$ & $84(45.2 \%)$ & $0.774 \pm 0.275$ & $0.893(-0.251-1)$ & $0.715-0.834$ & \\
\hline $13-24$ & $45(24.2 \%)$ & $0.758 \pm 0.280$ & $0.882(-0.222-1)$ & $0.674-0.842$ & \\
\hline$\geq 24$ & $57(30.6 \%)$ & $0.787 \pm 0.220$ & $0.831(0.022-1)$ & $0.729-0.845$ & \\
\hline Anxiety & $10.97 \pm 2.29$ & & & & 0.236 \\
\hline Normal & $11(5.9 \%)$ & $0.923 \pm 0.087$ & $0.9513333333433(0.738-1)$ & $0.865-0.982$ & \\
\hline Mild & $72(38.7 \%)$ & $0.776 \pm 0.307$ & $0.902(-0.251-1)$ & $0.704-0.849$ & \\
\hline Moderate & $90(48.4 \%)$ & $0.761 \pm 0.225$ & $0.804(-0.160-1)$ & $0.713-0.808$ & \\
\hline Severe & $13(7 \%)$ & $0.731 \pm 0.272$ & $0.699(0.312-1)$ & $0.567-0.896$ & \\
\hline Depression & $7.9 \pm 2.21$ & & & & 0.979 \\
\hline Normal & $83(44.6 \%)$ & $0.779 \pm 0.262$ & $0.841(-0.251-1)$ & $0.721-0.836$ & \\
\hline Mild & $81(43.5 \%)$ & $0.770 \pm 0.262$ & $0.885(-0.222-1)$ & $0.712-0.828$ & \\
\hline Moderate & $22(11.8 \%)$ & $0.773 \pm 0.253$ & $0.871(0.083-1)$ & $0.662-0.886$ & \\
\hline Social support & $37.21 \pm 7.97$ & & & & $<0.001^{* *}$ \\
\hline Low & $8(4.3 \%)$ & $0.623 \pm 0.108$ & $0.632(0.493-1)$ & $0.533-0.713$ & \\
\hline Moderate & $133(71.5 \%)$ & $0.735 \pm 0.276$ & $0.824(-0.251-1)$ & $0.688-0.783$ & \\
\hline High & $45(24.2 \%)$ & $0.917 \pm 0.155$ & $1.0(0.262-1)$ & $0.870-0.963$ & \\
\hline Family function (APGAR score) (Mean \pm SD) & $6.86 \pm 1.81$ & & & & $<0.001^{* *}$ \\
\hline Severely dysfunctional $(n, \%)$ & $47(25.3 \%)$ & $0.698 \pm 0.246$ & $0.734(-0.164-1)$ & $0.848-0.937$ & \\
\hline Moderate dysfunctional (n, \%) & $89(47.8 \%)$ & $0.749 \pm 0.291$ & $0.848(-0.251-1)$ & $0.687-0.810$ & \\
\hline
\end{tabular}


Table 2 (continued)

\begin{tabular}{|c|c|c|c|c|c|}
\hline & $N=186$ & Mean \pm SD & Median(range) & $95 \% \mathrm{Cl}$ & $P$ values \\
\hline Highly functional $(n, \%)$ & $50(26.9 \%)$ & $0.892 \pm 0.156$ & $0.947(0.262-1)$ & $0.625-0.770$ & \\
\hline ECOG score & & & & & $<0.001^{* *}$ \\
\hline 0 & $43(23.1 \%)$ & $0.939 \pm 0.133$ & $1.0(0.475-1)$ & $0.898-0.979$ & \\
\hline 1 & $97(52.2 \%)$ & $0.794 \pm 0.203$ & $0.893(0.083-1)$ & $0.753-0.835$ & \\
\hline 2 & $34(18.3 \%)$ & $0.643 \pm 0.237$ & $0.725(-0.017-1)$ & $0.560-0.725$ & \\
\hline 3 & $12(6.5 \%)$ & $0.403 \pm 0.475$ & $0.520(-0.251-1)$ & $0.102-0.705$ & \\
\hline Comorbidities & & & & & $<0.001^{* *}$ \\
\hline No & $136(73.1 \%)$ & $0.836 \pm 0.184$ & $0.893(0.022-1)$ & $0.805-0.868$ & \\
\hline Yes & $50(26.9 \%)$ & $0.606 \pm 0.348$ & $0.585(-0.251-1)$ & $0.506-0.705$ & \\
\hline
\end{tabular}

CNY¥ represents Chinese Yuan; USD \$ represents US dollar

Table 3 Influencing factors of EQ-5D-5L utility scores from Tobit regression model

\begin{tabular}{|c|c|c|c|}
\hline Variables & Coefficient & SE & $P$ values \\
\hline \multicolumn{4}{|l|}{ Religious belief } \\
\hline Yes & Ref & & \\
\hline No & -0.075 & 0.031 & $0.017^{*}$ \\
\hline \multicolumn{4}{|l|}{ Medical insurance } \\
\hline Yes & Ref & & \\
\hline No & -0.293 & 0.097 & $0.003^{*}$ \\
\hline \multicolumn{4}{|l|}{ Comorbidities } \\
\hline No & Ref & & \\
\hline Yes & -0.133 & 0.038 & $0.001^{*}$ \\
\hline \multicolumn{4}{|l|}{ Type of leukemia } \\
\hline AML & Ref & & \\
\hline ALL & -0.102 & 0.065 & 0.119 \\
\hline \multicolumn{4}{|l|}{ Social support } \\
\hline High & Ref & & \\
\hline Moderate & -0.117 & 0.043 & $0.007^{*}$ \\
\hline Low & -0.309 & 0.115 & $0.008^{*}$ \\
\hline \multicolumn{4}{|c|}{ Family function (APGAR score) } \\
\hline Highly functional & Ref & & \\
\hline Moderate dysfunctional & -0.041 & 0.039 & 0.296 \\
\hline Severely dysfunctional & -0.106 & 0.055 & 0.056 \\
\hline \multicolumn{4}{|l|}{ ECOG score } \\
\hline 0 & Ref & & \\
\hline 1 & -0.302 & 0.124 & $0.016^{*}$ \\
\hline 2 & -0.396 & 0.153 & $0.010^{*}$ \\
\hline 3 & -0.514 & 0.194 & $0.009^{*}$ \\
\hline
\end{tabular}

the relationships between comorbidity, ECOG performance, and HRQoL for leukemia patients [45]. Therefore, these results in the current study indicated that the ECOG and comorbidities can be robust predictors of HRQoL and offer information to assist clinicians in decision-making.
In some previous studies, social support had been identified as an important factor associated with improved quality of life for some solid cancer patients (e.g., breast cancer [46] and lung cancer [47]). Compared to the cancer population with solid tumor, individuals with leukemia are at higher risk of potential life-threatening experience, prolonged treatment with adverse effects, and catastrophic economic burden $[23,25]$. In line with a few studies in which leukemia patients with higher levels of social support were found to have better HRQoL [48, 49], the present study found perceived social support to be an important predictor of better HRQoL. Therefore, it is essential to build a good social support network for the vulnerable leukemia population.

\section{limitations}

There were some limitations in this study. First, this study surveyed inpatients with leukemia in tertiary hospitals without inclusion of outpatients. Second, our study did not include patients with CML and CLL which are rare types of leukemia in Chinese adults and our study sample is at best only regionally representative. Therefore, the findings of our study may not be generalizable to other geographic areas of the country. Third, what we observed are associations between characteristics and HRQoL of leukemia patients in a context of cross-sectional survey. Causal relationships should be investigated in future longitudinal studies. Lastly, some potential factors of HRQoL such as cancer stage and therapeutic modalities were not investigated. Those should be explored in future studies.

\section{Conclusion}

This study indicated that leukemia patients have lower health utility and poor health status compared to the general Chinese population and that there are multiple factors affecting the patients' health utility. Given the 
limited health utility data for leukemia patients, the utility scores reported in this study could be useful in future cost-utility analysis (CUA) of treatments for leukemia.

\section{Acknowledgements}

We are especially grateful to the participants who have suffered from leukemia and have never given up.

\section{Authors' contributions}

$X Z$, MS and RL drafted the manuscript and performed the data analysis. EZ, JY and $\mathrm{CL}$ collected data and interpreted of results. $\mathrm{WH}, \mathrm{HY}$ and $\mathrm{HY}$ contributed to study design and draft/edit the manuscript. XQ and NL contributed to review/edit the manuscript. All author read and approved the final manuscript.

\section{Funding}

This work was funded by the National Social Science Foundation of China (Grant Nos. 71974048, 71503062) and by the China Medical Board (CMB-19-308)

\section{Availability of data and materials}

Data can be obtained from the corresponding author under reasonable request.

\section{Ethics approval and consent to participate}

All procedures performed in studies involving human participants were in accordance with the ethical standards and were approved by the Regional Ethical Committee, Harbin Medical University.

\section{Consent for publication}

Not applicable.

\section{Competing interests}

The authors declare no competing interests.

\section{Author details \\ 1 School of Health Management, Harbin Medical University, Harbin 150086, China. ${ }^{2}$ National University Singapore Saw Swee Hock School of Public Health, Singapore 117549 , Singapore. ${ }^{3}$ Department of Hematology, The First Affiliated Hospital of Harbin Medical University, Harbin 150001, China. ${ }^{4}$ First Affiliated Hospital of Harbin Medical University, Harbin 150001, China. ${ }^{5}$ Public Health Education and Information Center of Heilongjiang Province, Harbin 150063, China. ${ }^{6}$ Department of Medical Oncology, Third Affiliated Hospital of Harbin Medical University, Harbin 150081, China. ${ }^{7}$ Southern University of Science and Technology Hospital, Shenzhen 518055, China.}

Received: 22 April 2020 Accepted: 18 February 2021

Published online: 27 February 2021

\section{References}

1. Bray F, Ferlay J, Soerjomataram I, Siegel RL, Torre LA, Jemal A. Global cancer statistics 2018: GLOBOCAN estimates of incidence and mortality worldwide for 36 cancers in 185 countries. CA Cancer J Clin. 2018;68:394-424.

2. Chen W, Zheng R, Baade PD, Zhang S, Zeng H, Bray F, Jemal A, Yu XQ, He J. Cancer statistics in China, 2015. CA Cancer J Clin. 2016;66(2):115-32.

3. Zeng H, Chen W, Zheng R, Zhang S, Ji JS, Zou X, et al. Changing cancer survival in China during 2003-15: a pooled analysis of 17 populationbased cancer registries. Lancet Global Health. 2018;6:e555.

4. Shanafelt TD, Bowen D, Venkat C, Slager SL, Zent CS, Kay NE, et al. Quality of life in chronic lymphocytic leukemia: an international survey of 1482 patients. Br J Haematol. 2010;139:255-64.

5. Molic S. Quality of life in chronic lymphocytic leukemia: a neglected issue. Leukemia Lymphoma. 2005;46:1709-14.

6. Cella D, Jensen SE, Webster K, Hongyan D, Lai JS, Rosen S, et al. Measuring health-related quality of life in leukemia: the Functional Assessment of Cancer Therapy-Leukemia (FACT-Leu) questionnaire. Value Health. 2012;15:1051-8.
7. Shanafelt TD, Deborah B, Chaya V, Slager SL, Zent CS, Kay NE, et al. Quality of life in chronic lymphocytic leukemia: an international survey of 1482 patients. Br J Haematol. 2010;139:255-64.

8. Fayers P, Bottomley A, Unit QOLJEJoC. Quality of life research within the EORTC-the EORTC QLQ-C30 European Organisation for Research and Treatment of Cancer. European Journal of Cancer.2002; 38(4): S125.

9. Holzner B, Kemmler G, Kopp M, Nguyen-Van-Tam D, Sperner-Unterweger B, Greil R. Quality of life of patients with chronic lymphocytic leukemia: results of a longitudinal investigation over 1 yr. Eur J Haematol. 2015;72:381-9.

10. Aaronson NK, Ahmedzai S, Bergman B, Bullinger M, Cull A, Duez NJ, et al. The European organization for research and treatment of cancer QLQC30: a quality-of-life instrument for use in international clinical trials in oncology. J Natl Cancer Inst. 1993;85:365-76.

11. van Dongen-Leunis A, Redekop WK, Uyl-de Groot CA. Which questionnaire should be used to measure quality-of-life utilities in patients with acute leukemia? An evaluation of the validity and interpretability of the EQ-5D-5L and preference-based questionnaires derived from the EORTC QLQ-C30. Value Health J IntSocPharmacoecon Outcomes Res. 2016;19:834-43.

12 Torrance GW. Measurement of health state utilities for economic appraisal : A review. J Health Econ. 1986;5:1-30.

13. Payakachat N, Ali MM, Tilford JMJP. Can The EQ-5D Detect Meaningful Change? A Syst Rev Pharm. 2015;33:1137-54.

14. Devlin NJ, Brooks R. EQ-5D and the EuroQol group: past, present and future. Appl Health Econ Health Policy. 2017;15:127-37.

15. NICE.NICE technology appraisal guidance. 2013.

16. Pashos CL, Flowers CR, Kay NE, Weiss M, Lamanna N, Farber C, et al. Association of health-related quality of life with gender in patients with B-cell chronic lymphocytic leukemia. Support Care Cancer. 2013;21:2853-60.

17. Herdman M, Gudex C, Lloyd A, Janssen M, Kind P, Parkin D, et al. Development and preliminary testing of the new five-level version of EQ-5D (EQ-5D-5L). Qual Life Res. 2011;20:1727-36.

18. Luo N, Liu G, Li M, Guan H, Jin X, Rand-Hendriksen K. Estimating an EQ5D-5L value set for China. Value Health. 2017;20:662-9.

19. Devlin NJ, Shah KK, Feng Y, Mulhern B, Van Hout BJHE. Valuing healthrelated quality of life: An EQ-5D-5L value set for England. Health Econ. 2016;27:7-22.

20. Ludwig K, Greiner WJP. German Value Set for the EQ-5D-5L. Pharmacoeconomics. 2018;36:663-74.

21. Choi YS, Hwang SW, Hwang IC, Lee YJ, Kim YS, Kim HM, et al. Factors associated with quality of life among family caregivers of terminally ill cancer patients. Psychooncology. 2016;25:217-24.

22. Holtzer-Goor KM, Schaafsma MR, Joosten P, Posthuma EF, Wittebol S, Huijgens PC, et al. Quality of life of patients with chronic lymphocytic leukaemia in the Netherlands: results of a longitudinal multicentre study. Qual Life Res. 2015;24:2895-906.

23. Yu H, Zhang H, Yang J, Liu C, Lu C, Yang H, et al. Health utility scores of family caregivers for leukemia patients measured by EQ-5D-3L: a crosssectional survey in China. BMC Cancer. 2018;18:950.

24. Cavusoglu H, Saglam H. Examining the perceived social support and psychological symptoms among adolescents with leukemia. J Spec PediatrNurs. 2015;20:76-85.

25. Santos FR, Kozasa EH, ChauffailleMde L, Colleoni GW, Leite JR. Psychosocial adaptation and quality of life among Brazilian patients with different hematological malignancies. J Psychosom Res. 2006;60:505-11.

26. Sakamaki H, Nakao K, Matsumoto T, Inoue S. Cost-effectiveness analysis of percutaneous mitral valve repair with the MitraClip delivery system for patients with mitral regurgitation in Japan. J Med Econ. 2019;22(12):1312-20.

27. Bjelland I, Dahl AA, Haug TT, Neckelmann DJ. The validity of the hospital anxiety and depression scale: an updated literature review. J Psychosom Res. 2002;52:69-77.

28. Fang TY, Cheng LJ, Wu DB, Wang PC. Cost-effective analysis of unilateral cochlear implantation under the Taiwan national healthcare insurance. Int J Audiol. 2019;59(1):39-44.

29. Xiao SJ. The theoretical basis and research applications of "Social Support Rating Scale. J Clin Psychiatry. 1994;4:98-100.

30. Morozova O, Crawford FW, Cohen T, Paltiel AD, Altice FL. Cost-effectiveness of expanding the capacity of opioid agonist treatment in Ukraine: dynamic modeling analysis. Addiction. 2019;115:437-50. 
31. Serra-Burriel M, Graupera I, Toran P, Thiele M, Roulot D, Wai-Sun Wong V, et al. Transient elastography for screening of liver fibrosis: Cost-effectiveness analysis from six prospective cohorts in Europe and Asia. J Hepatol. 2019;71:1141-51.

32. Yang Z, Busschbach J, Liu G, Luo N. EQ-5D-5L norms for the urban Chinese population in China. Health Qual Life Outcomes. 2018;16:210.

33. Research AMJ, Practice TfN. Quality of Life: The Assessment, Analysis and Interpretation of Patient-Reported Outcomes (2nd Ed.). Theory for Nursing Practice. 2009; 23: 78-79.

34. Huang W, Yang J, Liu Y, Liu C, Zhang X, Fu W, et al. Assessing health-related quality of life of patients with colorectal cancer using EQ-5D-5L: a crosssectional study in Heilongjiang of China. BMJ Open. 2018;8:e022711.

35. Leunis A, Redekop WK, Uyl-de Groot CA, Lowenberg B. Impaired healthrelated quality of life in acute myeloid leukemia survivors: a single-center study. Eur J Haematol. 2014;93:198-206.

36. Park CL. Spirituality and meaning making in cancer survivorship. The psychology of meaning. 2013; p.257-277.

37. Alcorn SR, Balboni MJ, Prigerson HG, Reynolds A, Phelps AC, Wright AA, et al. "If God wanted me yesterday, I wouldn't be here today": religious and spiritual themes in patients' experiences of advanced cancer. J Palliat Med. 2010;13:581-8.

38. Préau M, Bouhnik AD, Le CSA, Group ACSJPH, Medicine. Two years after cancer diagnosis, what is the relationship between health-related quality of life, coping strategies and spirituality? Psychology Health Medicine. 2013; 18: 375-386.

39. Jim HS, Pustejovsky JE, Park CL, Danhauer SC, Sherman AC, Fitchett G, et al. Religion, spirituality, and physical health in cancer patients: A metaanalysis. Cancer. 2015;121:3760-8.

40. Yang Y, Huang S. Religious beliefs and environmental behaviors in China. Religions. 2018;9:72.

41. Sheng G, Chen S, Zhang R, Miao M, Wu D, Tan SC, et al. The impact of medical insurance coverage and molecular monitoring frequency on outcomes in chronic myeloid leukemia: real-world evidence in China. J Med Econ. 2016;20:382-7.

42. Rochagarcía A, Hernándezpeña P, Ruizvelazco S, Avilaburgos L, Marínpalomares T, Lazcanoponce EJSPDM. Out-of-pocket expenditures during hospitalization of young leukemia patients with state medical insurance in two Mexican hospitals. Salud Pública De Mexico. 2003; 45: 285-292.

43. Gebru T, Lentiro K. The impact of community-based health insurance on health-related quality of life and associated factors in Ethiopia: a comparative cross-sectional study. Health Qual Life Outcomes. 2018;16:110.

44. Chiu SYR, Yang Z. Influence of family income and medical insurance coverage on health-related quality of life and optimism in cancer patients at a Hong Kong private hospital: a cross-sectional study. Psychooncology. 2019:28:1971-7.

45. Flowers C, Pashos CL, Weiss MA, Lamanna N, Farber CM, Kipps TJ, et al. Variation in health-related quality of life (HRQOL) by ECOG performance status (PS) and fatigue among patients with chronic lymphocytic leukemia (CLL). J ClinOncol. 2011:30:6122.

46. Kroenke CH, Kwan ML, Neugut Al, Ergas IJ, Wright JD, Caan BJ, et al. Social networks, social support mechanisms, and quality of life after breast cancer diagnosis. Breast Cancer Res. 2013;139:515-27.

47 Luszczynska A, Pawlowska I, Cieslak R, Knoll N, Scholz U. Social support and quality of life among lung cancer patients: a systematic review. Psycho-Oncology. 2013;22:2160-8.

48. Pailler ME, Johnson TM, Kuszczak S, Attwood KM, Zevon MA, Griffiths E, et al. Adjustment to Acute Leukemia: The Impact of Social Support and Marital Satisfaction on Distress and Quality of Life Among Newly Diagnosed Patients and Their Caregivers. J ClinPsychol Med Settings. 2016:23:298-309.

49. Efficace F, Breccia M, Cottone F, Okumura I, Doro M, Riccardi F, et al. Psychological well-being and social support in chronic myeloid leukemia patients receiving lifelong targeted therapies. Support Care Cancer. 2016;24:4887-94.

\section{Publisher's Note}

Springer Nature remains neutral with regard to jurisdictional claims in published maps and institutional affiliations.
Ready to submit your research? Choose BMC and benefit from:

- fast, convenient online submission

- thorough peer review by experienced researchers in your field

- rapid publication on acceptance

- support for research data, including large and complex data types

- gold Open Access which fosters wider collaboration and increased citations

- maximum visibility for your research: over $100 \mathrm{M}$ website views per year

At $\mathrm{BMC}$, research is always in progress.

Learn more biomedcentral.com/submissions 